\title{
Global warming potential revisited
}

\author{
N. Marchettini, M. Marchi \& E. Tiezzi \\ Department of Chemistry, University of Siena, Italy
}

\begin{abstract}
The greenhouse effect is a core problem as far as air pollution, climate changes, environmental risk and ecological policies are concerned. According to the IPCC, the uncertainties associated with specifying the lifetime of $\mathrm{CO}_{2}$ means that presentation of the GWP (Global Warming Potential) relative to $\mathrm{CO}_{2}$ may not be the ideal choice; moreover a reductionist approach based on actual lifetime due to the transfer of $\mathrm{CO}_{2}$ amongst the different reservoirs is not scientifically correct since from a thermodynamic point it is necessary to consider the entire cycle of $\mathrm{CO}_{2}$ in the throughout biological evolution (billions of years). James Hansen recently stated that about one-quarter of fossil fuel $\mathrm{CO}_{2}$ emissions will stay in the air "forever". In the present paper we discuss the following points:

a) the comparison between the atmosphere of Venus, of the Earth before the appearance of life, Mars and the Earth during the biological evolution;

b) the different equations related to GWP;

c) a case study of the Italian region of Abruzzo.

Since anthropogenic emissions over a few decades (an infinitesimal interval on the biological scale) have increased the concentration of $\mathrm{CO}_{2}$ in the atmosphere from $250 \mathrm{ppm}$ to almost $400 \mathrm{ppm}$, the environmental effects are enormous, both for ecosystems and the economy. Recently, on Nature, Cox et al. claim that the terrestrial biosphere will take up $\mathrm{CO}_{2}$ at a decreasing rate after about 2010, becoming a net source by around 2050. By 2100 this source from the land almost balances the oceanic sink.
\end{abstract}

Keywords: GWP, greenhouse effect, case study on Region Abruzzo.

\section{Introduction}

The greenhouse effect is a natural phenomenon, present on Planet Earth for millions of years. Every ton of coal burned produces three tons of carbon dioxide. In 22 years the carbon dioxide in the atmosphere has increased by 
20 ppm, equivalent to 42 billion tons of coal. From the industrial revolution to today it is calculated that the carbon added to the atmosphere has been 85 billion tons, when the total quantity of carbon in the atmosphere is only 700 billion tons. Bolin [1] of Stockholm University, world expert on land biota and the carbon cycle, writes that man has unwittingly triggered a global geochemical and climatic experiment that could easily get out of control; the sorcerer's apprentice does experiments on himself without knowing how to stop the process.

The effects can already be felt; ranging from desertification in various parts of the world, to increased evaporation and consequent flash floods, and decrease in size of the polar ice caps.

The energy absorbed is radiated back to Earth, increasing the total flux of radiant energy on the Earth's surface. This is the process known as the greenhouse effect.

It has been estimated that the Earth's surface would be $30-40^{\circ} \mathrm{C}$ colder without this additional energy flux. The surface of Mars is at $-50^{\circ} \mathrm{C}$ because of the rarefaction of its atmosphere, whereas the surface of Venus, the atmosphere of which contains an abundance of carbon dioxide, is at more than $400^{\circ} \mathrm{C}$.

The atmosphere of Venus is $96.5 \%$ carbon dioxide, a quantity lethal for any form of life because it determines a surface temperature of more than $400^{\circ} \mathrm{C}$. By contrast, the Earth's atmosphere is $0.033 \%$ carbon dioxide, just enough to ensure warm springs and hot summers. However, the concentration of carbon dioxide in the Earth's atmosphere has increased from about $250 \mathrm{ppm}$ (parts per million) to about $380 \mathrm{ppm}$ in the last fifty years. This is an enormous increase in such an infinitesimally brief moment in the scale of biological time. The main cause of the increase is the use of fossil fuels. These release about 5.4 gigatons (1015 grammes) of carbon into the atmosphere in a year. The second cause is the clearing of forests at a rate of 20 million hectares per year. This releases 1.6 gigatons of carbon per year. The third cause is related to cement production with a further 0.1 gigatons per year. The natural rate of absorption of the oceans and of photosynthesis cannot keep up with the pace of technology and the millennial equilibrium of energy flows of the biosphere is at risk for the first time in the history of the planet.

The Earth's atmosphere enabled life to form and evolution to take place; it made it possible for photosynthesis to increase the percentage of oxygen in the atmosphere two billion years ago; it originates from a long and complex history of evolutionary processes and feedbacks. Due to the "sorcerer's apprentices" of the last fifty years, it may become a lifeless Venusian atmosphere. Complex mathematical models of the greenhouse effect are unable to predict how the oceans will respond, how the modified feedback mechanisms will act, how the climate will change. It is a stupid adventure for sorcerer's apprentices of an unlikely Venusian story. Evading the control of the equations of Lotka and Volterra, they are tampering with one of the vital ganglions of our biosphere.

Alfonso M. Liquori, University "La Sapienza" of Rome, first studied the comparison between Venus and Earth some decades ago. Figure 1 shows this comparison. 


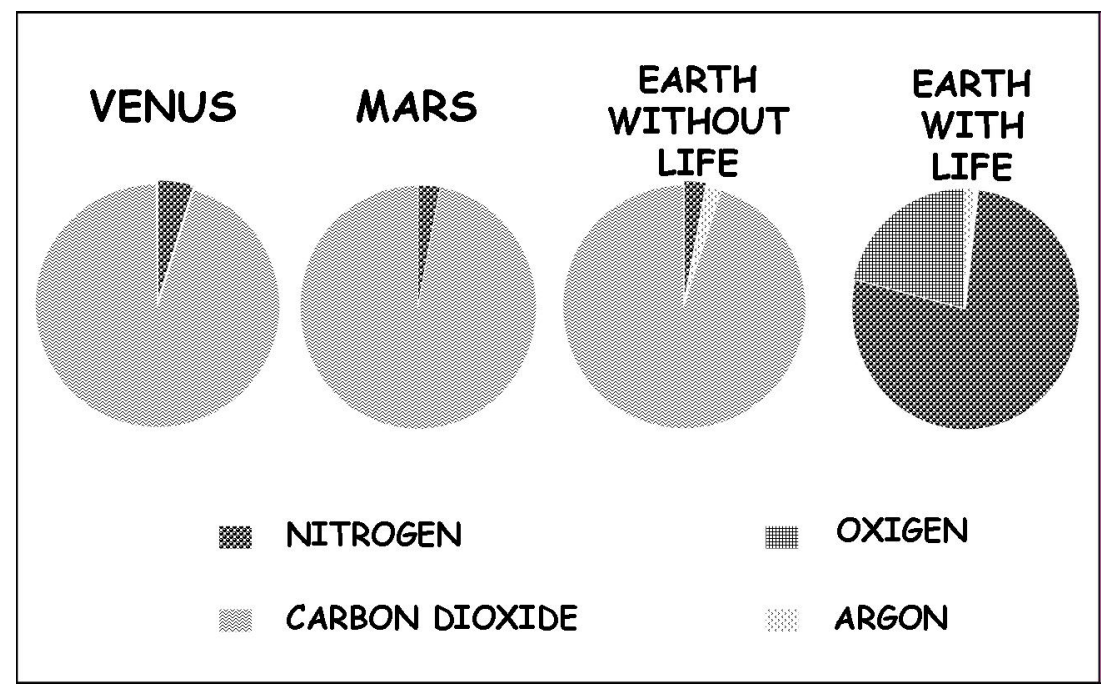

Figure 1: $\quad$ The origin of life.

Tiezzi [2, 3] showed the thermodynamic implication of this behaviour in terms of negentropy. Table 1 shows the story of Planet Earth compared with one year of time range.

Table 1: $\quad$ The Birth of the Earth (MY = million years).

\begin{tabular}{lll}
\hline $4,600 \mathrm{MY}$ & Jan 1 & Birthday \\
$3,500 \mathrm{MY}$ & April 1 & $\mathrm{CO}_{2}+\mathrm{H}_{2} \mathrm{O} \rightarrow \mathrm{CH}_{2} \mathrm{O}+\mathrm{O}_{2}$ \\
$500 \mathrm{MY}$ & Oct 30 & Ozone \\
$400 \mathrm{MY}$ & Nov 8 & $21 \% \mathrm{O}_{2}$ \\
$350 \mathrm{MY}$ & Nov 15 & Soil Formation \\
$200 \mathrm{MY}$ & $\operatorname{Dec} 26$ & Dinosaur \\
$65 \mathrm{MY}$ & $\operatorname{Dec} 30$ & Dinosaur Death, \\
& & Meteoritic Bombardment \\
$1,7 \mathrm{MY}$ & Dec $31 \quad$ Noon & Huminidae Appearance \\
$0,0002 \mathrm{MY}$ & Dec $31 \quad 23.59 .59 .99$ & The Industrial Revolution \\
\hline
\end{tabular}

In ninety years, some new parameters, able to give an assessment of the impacts due to the anthropogenic emissions, were elaborated: the Global Warming Potentials (GWPs), numerical indices introduced to compare the contribution of various greenhouse gases to global warming, supplying an assessment of the long term effects on the climatic system and the "equivalent" emissions of $\mathrm{CO}_{2}\left(\mathrm{CO}_{2 \mathrm{eq}}\right)$ [4]. We use these indices in order to improve the understanding of a complex environmental problem, like the greenhouse effect. 


\section{General discussion}

It is well known that the analytical model of GWPs is, and has been object of numerous criticisms for the limits related to the understanding of the thermodynamic interactions that characterizes the climatic system. The first limit, in order of importance, is relative to the lifetime chosen for the carbon dioxide $\left(\mathrm{CO}_{2}\right)$, the reference gas; in fact, a reductionist approach based on actual lifetime due to the transfer of $\mathrm{CO}_{2}$ amongst the different reservoirs is not scientifically correct from a thermodynamic point of view [5].

Moreover, with the use of the GWPs, we can fall in other specific errors, like resorting to the climatic effects given from the release in atmosphere of an instantaneous impulse in order to assess the radiative forcing intensity of a gas or to consider the emissions of the real world, constants and limited in the time [4].

In this paper, some of the numerous criticisms on the GWPs will be newly discussed, pointing out particularly the role of carbon dioxide, the greenhouse gas that provoke greater worries for its enormous release in atmosphere as a result of the anthropogenic activities and for its ability in altering the carbon cycle. Moreover, it will be dealt the case study of the Italian region of Abruzzo, to deepen also from the practical point of view the error which we have using the GWP index in the calculation of the $\mathrm{CO}_{2 \text { eq }}$, considered corrected only hypothetically [6].

\subsection{Tipping point}

Our planet is dangerously near to a tipping point since the emissions of greenhouse gases from the human activities, and in particular way from the combustion of the fossil fuels, could carry to $459 \mathrm{ppm}$ of carbon dioxide in the atmosphere [7].

The serious effects due to the increase of temperature are already existing and are provoking the uncontrolled shift of the climatic areas, the decrease of fresh water availability and problems for human health. The possible effects of climate warming for the end of the next century are worrying, in fact, an increase of temperature will carry to the elevation of the sea level of more than half a meter and to an increment of rains, caused from the increase of the mean level of evaporation of waters, especially at high latitudes. These phenomena are altering the complex equilibria of the ecosystems carrying to the decrease of biodiversity and to a progressive desertification. The effects due to the increase of the temperatures will be dangerous for nature and living species [8]. Today, after 3 Myr of stability, a drastic change of carbon dioxide in the atmosphere can be observed: the millenary equilibrium between feedbacks and homeostasis that have favoured the two cycles on which life is based, the carbon and oxygen cycles, has been troubled.

James Hansen recently stated that about one-quarter of fossil fuel $\mathrm{CO}_{2}$ emissions will stay in the air "forever", sure more than 500 years, time taken like practical definition of forever because it is long enough for large responses [9]. 
Following the calculations of the Bern carbon cycle model [10], one-third of the emitted $\mathrm{CO}_{2}$ is still in the air after a century, and almost one-quarter is still there after five century; however, this is an optimistic point of view, being valid only for moderate $\mathrm{CO}_{2}$ emission rates in the atmosphere. In fact, with a "business-as-usual" emissions, characterized by enormous combustion of fossil fuels, the ocean chemistry becomes notably non linear for the increasing "Revelle buffer factor" and the biosphere is expected to become less effective at $\mathrm{CO}_{2}$ uptake $[11 ; 12]$.

Recently, on Nature [13], Cox et al. claim that the terrestrial biosphere will take up $\mathrm{CO}_{2}$ at a decreasing rate after about 2010, becoming a net source by around 2050. By 2100 the uptake of carbon dioxide from the oceans will be balanced from the emissions due to an accelerated respiration of the ground. Moreover, the excess of $\mathrm{CO}_{2}$ in atmosphere can determine the saturation of the enzyme for the photosynthesis.

\section{Global warming potential and other mathematical models to compare the direct emissions of different greenhouse gases}

In 1990, the Intergovernmental Panel on Climate Change (IPCC) presented the Global Warming Potential index [5], which later was adopted in the Kyoto Protocol for comparing the climate impacts of emissions of greenhouse gases. This particular index was, from the first moment, the subject of open debates. In order to support their improvement, or directly their substitution, numerous alternative metrics were proposed.

The GWPs were presented for the first time to the political world, like infallible models in their formulation, although their uncertainties in the methodology. In fact, the authors of a relevant IPCC chapter for the emissions of greenhouse gases said that it could not be accepted from all since closely connected to the cycle-climate models of the gases and needed of reviews and new investigations. Despite the above provisos, the IPCC provided a table of figures giving the direct and indirect GWPs for a wide range of greenhouse gases $\left(\mathrm{CO}_{2}, \mathrm{CFC}_{\mathrm{s}}, \mathrm{HCFC}_{\mathrm{s}}, \mathrm{CH}_{4}, \mathrm{CO}, \mathrm{NMHC}, \mathrm{NO}_{\mathrm{x}}\right.$ e $\left.\mathrm{N}_{2} \mathrm{O}\right)[14,15]$.

The metric formulation will differ depending on whether a long-term climate change constraint has been set or no specific long-term constrain has been agreed upon, as in the Kyoto Protocol. Either metric formulation requires knowledge of the contribution to climate change from emissions of various components over time [16].

A general formulation of an emission metric is given by Kandlikar for the metric value AMi:

$$
A M i=\int_{0}^{\infty}\left[\left(I \Delta C_{(r+i)}(t)-I\left(\Delta C_{r}(t)\right) x g(t)\right] d t\right.
$$

where $I\left(\Delta C_{i}(t)\right)$ is a function describing the damages and the benefits (impacts) of change in climate $(\Delta C)$ at time $t$. The expression $g(t)$ is a weighting function over 
time, while the subscript $r$ refers to a baseline emission path, that is present in atmosphere before the emission $i$.

The general parameter proposed by Kandlikar has several problematic issues related to defining an appropriate impact function of every emission scenarios. Other problematic issues include the definition of the temporal weighting function $g(t)$ and the baseline emission scenarios [16].

Due to these difficulties, the simpler and purely physical GWP index was developed [5]. The GWP has been defined as the ratio of the time-integrated radiative forcing from the instantaneous release of $1 \mathrm{~kg}$ of a trace substance relative to that of $1 \mathrm{~kg}$ of a reference gas:

$$
G W P(x)=\frac{\int_{0}^{T H} a_{x} \cdot[x(t)] d t}{\int_{0}^{T H} a_{r} \cdot[r(t)] d t}
$$

where $T H$ is the time horizon over which the calculation is considered $(20,100$ and 500 years), $a_{x}$ is the radiative forcing due to a unit increase in atmospheric abundance of the substance in question $\left(\mathrm{Wm}^{-2} \mathrm{~kg}^{-1}\right) ;[\mathrm{x}(\mathrm{t})]$ is the lifetime of this gas in atmosphere; the corresponding quantities for the reference gas are in the denominator [17].

The simplifications made to derive the standard GWP index include some approximations. Therefore, the GWPs of the IPCC have been hardly simplified, and this has been the cause of the numerous criticisms from the scientific world [16]. A very important limitation of the GWPs is that the relationship between emissions and radiative forcing is non-linear and for this difficulty the IPCC chose a particular approximation: infinitesimal perturbations around the current atmospheric composition. Smith and Wigley consider this choice to be unrealistic because the composition of the atmosphere is changing as a result of a "business-as-usual" emissions scenario [18].

Such a variation determines a lot of alterations on the natural cycles, the uptake and the transformation of gases and therefore the increase in the emissions carry to different lifetimes in atmosphere (greater permanence times for the $\mathrm{CO}_{2}$ ), provoking greater errors [19].

Thus it can be asserted that the choice for $\mathrm{CO}_{2}$, of a mean lifetime of 120 years, like on the $1^{\text {st }}$ Report of the IPCC, is wrong because it does not consider the exponential increase in atmosphere of this gas for the uncontrolled use of the fossil fuels.

Citing the words of Archer [20]: "A better approximation of the lifetime of fossil fuel $\mathrm{CO}_{2}$ for public discussion might be 300 years, plus $25 \%$ that lasts forever". Recently, Shine et al. [21] proposed an alternative relative emission metric to the GWP for comparing climate impacts of emissions of greenhouse gases: the first metric is called the Global Temperature Change Potential and represents the temperature change at a given time due to a pulse emission of a gas $\left(\mathrm{GTP}_{\mathrm{p}}\right)$ and the second represents the effect of a sustained emission change $\left(\mathrm{GTP}_{\mathrm{s}}\right)$. These new parameters have a lot of advantages on the GWP because they represent the global mean surface temperature change, assessing the climate efficacies due to greenhouse gases emissions. The GTP index requires 
knowledge of the same parameters as the GWP metric, but in addition, the response times for the climate system. The $\mathrm{GTP}_{\mathrm{s}}$ is quite similar to the GWP and so it can to be used as an alternative parameter.

In this new parameter the greater lifetime used, is 421 years, an infinitesimal interval time in comparison to billions of years for the natural cycles adjustment and for the biological evolution. In fact, the GTPs, with time of horizon of 100 years, of gas methane is 25 , value much similar to that of the GWP on the Third Assessment Report of the IPCC.

Moreover, it would be important to account that part of anthropogenic $\mathrm{CO}_{2}$ that remains in the atmosphere for million of years and not the several step of $\mathrm{CO}_{2}$ uptake from the natural biological cycles, which is a reductionist approach.

In any comprehensive approach, emissions reductions in different greenhouse gases must be converted to a common unit so that reductions in one gas can be compared directly with reductions in another greenhouse gas.

It has been assumed that an "equivalent" change in carbon dioxide emissions may be found using the relation:

$$
\triangle E C O_{2}=\Delta E_{x} G W P_{x}
$$

Here, $\triangle E \mathrm{CO}_{2}$ is the change in $\mathrm{CO}_{2}$ emissions that is, through this relationship, judged to be "equivalent" to an emissions change $\Delta E_{x}$. The conventional GWPs vary considerably with time horizon and produce serious errors when applied to realistic scenarios [22].

An alternative, in order to limit this error, is to calculate the radiative forcing change assuming emissions changes in $\mathrm{CO}_{2}$ alone, and then, via an inverse calculation, to determine the year-by-year emissions changes for gas $\mathrm{X}$ that lead to the same radiative forcing change:

$$
F E I_{x}=\Delta E C O_{2}(t) / \Delta E_{x}(t)
$$

This parameter proposed by Wigley [6], has been called Forcing Equivalence Index (FEI), an identity, while equation (3) is a relationship that is only hypothesized as being correct.

\subsection{The case study of Abruzzo}

In this paper, we propose to apply the FEI to a real system, proposing the comparison between the calculation of the $\mathrm{CO}_{2 \mathrm{eq}}$, like previewed from the Kyoto Protocol and in the Guidelines proposed from IPCC for the Greenhouse Gases Inventories, and Wigley's alternative index, for the first time.

The considered emissions are released in the atmosphere for the combustion of LPG, natural gas, diesel oil used for residential and service heating for the Italian region of Abruzzo. The emissions have been assessed using the new methodology and the emission factors proposed by the IPCC in 2006 [23], while for the quantitative of fossil fuels we have used the published data on the bulletin of the oil sales reported by the Ministry for year 2006 [24].

In Table 2 are shown the tons of carbon dioxide, methane and nitrous oxide emitted in atmosphere, for this activity and the correspondents equivalent- $\mathrm{CO}_{2}$ 
emissions, calculated applying equation (3) and considering the GWPs values of $\mathrm{CH}_{4}$ and $\mathrm{N}_{2} \mathrm{O}, 25$ and 298 respectively, so we need 25 and 298 instantaneous emissions of $\mathrm{CO}_{2}$ to catch up the same climatic effects determined from radiative forcing of a single impulse of $\mathrm{CH}_{4}$ and $\mathrm{N}_{2} \mathrm{O}$.

Now it is immediately possible to evidence the difference in the numerical scale between the $\mathrm{CO}_{2}$ emissions and those of the others two gases, whose concentration is lower than the carbon dioxide, that on the contrary, is released in atmosphere in enormous amounts.

The equivalent- $\mathrm{CO}_{2}$ emissions for the $\mathrm{CH}_{4}$ and the $\mathrm{N}_{2} \mathrm{O}$ emissions are reported in Table 3 .

The low concentration of $\mathrm{CH}_{4}$ and $\mathrm{N}_{2} \mathrm{O}$ in the atmosphere increases considerably of importance after to be multiplied for the GWP values, because also a gas with a lifetime lower than the reference gas, but with a higher radiative forcing, can cause some serious climatic impacts, according to this reductionist approach.

This approach considers only an instantaneous emission of a gas and not its variation on concentration during time.

In Table 4 we show the tons of methane and nitrous oxide that would have to be released in atmosphere in order to obtain the same radiative forcing provoked from the emissions of $\mathrm{CO}_{2}$. We have applied this alternative parameter.

Table 2: Annual emissions from combustion of LPG, natural gas and diesel oil for the residential and service sector heating for the Region of Abruzzo.

\begin{tabular}{|l|r|r|r|r|}
\hline \multicolumn{5}{|c|}{ Annual Emissions from Direct Combustion } \\
\hline Sector & $\mathbf{t ~ C O}_{\mathbf{2}}$ & $\mathbf{t ~ C H}_{\mathbf{4}}$ & $\mathbf{t ~ N}_{\mathbf{2}} \mathbf{O}$ & TOTAL $\mathbf{~} \mathbf{C O}_{\mathbf{2 e q}}$ \\
\hline Heating & $1,292,755$ & 24 & 3 & $1,294,115$ \\
\hline
\end{tabular}

Table 3: Equivalent $\mathrm{CO}_{2}$ emissions due to the methane and nitrous oxide emissions for this activity.

\begin{tabular}{|lr|r|r|}
\hline \multicolumn{2}{|c|}{ Annual Emissions no-CO $\mathbf{O}_{\mathbf{2}}$ from Direct Combustion } \\
\hline & $\mathbf{k g}$ & $\mathbf{t ~ C O}_{\mathbf{2 e q}}$ \\
\hline $\mathbf{C H}_{\mathbf{4}}$ & & \\
\hline & Heating & 23,876 & 597 \\
\hline $\mathbf{N}_{\mathbf{2}} \mathbf{O}$ & & 763 \\
\hline & Heating & 2,561 & 1,360 \\
\hline TOTAL & & \multicolumn{2}{c}{} \\
\hline
\end{tabular}

Table 4: $\quad$ Forcing Equivalence Index (FEI).

\begin{tabular}{|c|c|c|c|}
\hline \multicolumn{4}{|c|}{ Annual Emission from Direct Combustion } \\
\hline Sector & $\mathrm{t} \mathrm{CO}_{2}$ & $\mathrm{t} \mathrm{CH}_{4 \mathrm{eq}}$ & $\mathrm{t} \mathrm{N}_{2} \mathrm{O}_{\mathrm{eq}}$ \\
\hline Heating & $1,292,755$ & 54,145 & 504,859 \\
\hline
\end{tabular}


Thus, we can obtain values that give a better characterization of the reality and of the characteristics of the system.

\section{References}

[1] Bolin, B., Changes of land biota and their importance for the carbon cycle, Science, 196, pp. 613-615, 1977.

[2] Tiezzi, E., The End of Time, WIT Press Publications: Southampton and Boston, pp. 200, 2003.

[3] Tiezzi, E., The Essence of Time, Wit Press Publications: Southampton and Boston, pp. 123, 2003.

[4] Smith, S.J. \& Wigley, T.M.L., Global Warming Potentials: 2. Accuracy. Climatic Change, 44, pp. 459-469, 2000; and Smith, S.J. \& Wigley, T.M.L., Global Worming Potentials: 1. Climatic implications of emissions reductions. Climatic Change, 44, pp. 445-457, 2000.

[5] Shine, K.P., Derwent, R.G., Wuebbles, D.J. \& Morcrette, J.J., Radiative Forcing of Climate. Climate Change 1990: The IPCC Scientific Assessment. Contribution of Working Group I to the 1st Assessment Report of the IPCC, eds. Cambridge University Press, Cambridge, United Kingdom and New York, NY, USA, 1990.

[6] Wigley, T.M.L., The Kyoto Protocol: $\mathrm{CO}_{2}, \mathrm{CH}_{4}$ and climate implications. Geophysical Research Letters, 25(13), pp. 2285-2288, 1998.

[7] Hansen, J., Tipping point: Perspective of a climatologist. State of the Wild 2008-2009: A Global Portrait of Wildlife, Wildlands, and Oceans. W. Woods, eds. Wildlife Conservation Society/Island Press, pp. 6-15, 2008.

[8] Bastianoni, S., Bosco, S., Marchettini, N. \& Tiezzi, E., Un incontro con Al Gore. La Chimica e l'Industria, 5, pp. 98-105, 2008.

[9] Hansen, J., Sato, M., Kharecha, P., Russell, G., Lea, D.W. \& Siddall, M., Climate change and trace gases. Philosophical Transactions of the Royal Society A, 365, 1925-1954, 2007.

[10] Joos, F., Bruno, M., Fink, R., Stoker, T.F., Siegenthaler, U., Le Querce C. \& Sarmiento, J.L., An Efficient and accurate representation of complex oceanic and biospheric models of anthropogenic carbon uptake. Tellus B, 48, pp. 397-417, 1996.

[11] Fung, I.Y., Doney, S.C., Lindsay, K. \& John, J., Evolution of carbon sinks in a changing climate. PNAS, 102(32), pp. 11201-11206, 2005.

[12] Jones, C.D., Cox, P.M. \& Huntingford, C., Climate-carbon cycle feedbacks under stabilization: uncertainty and observational constraints. Tellus, 58B, 603-613, 2006.

[13] Cox, P.M., Betts, R.A., Jones C.D., Spall S.A. \& Totterdell, I.J., Acceleration of global warming due to carbon-cycle feedbacks in a coupled climate model. Letters to Nature, 408, pp.184-187, 2000.

[14] Godal, O., The IPCC's assessment of multidisciplinary issues: the case of greenhouse gas indices. An Editorial Essay. Climatic Change, 58, pp. 243 249, 2003. 
[15] Shackley, S. \& Wynne, B., Global Warming Potentials: ambiguity or precision as an aid to policy? Climate Research, 8, pp.89-106, 1997.

[16] Forster, P., Ramaswamy, V., Artaxo, P., Berntsen, T., Bettes, R., Fahy, D.W., Haywood, J., Lean, J., Lowe, D.C., Myhre, G., Nganga, J., Prinn, R., Raga, G., Schulz, M. \& Van Doland, R., Changes in Atmospheric Constituents and Radiative Forcing. Climate Change 2007: The Physical Science Basis. Contribution of Working Group I to the 4th Assessment Report of the IPCC, eds. Cambridge University Press, Cambridge, United Kingdom and New York, NY, USA, 2007.

[17] Boucher, O., Haigh, J., Hauglustaine, D., Haywood, J., Myhre, G., Nakajima, T., Shi, G.Y. \& Solomon, S., Radiative Forcing of Climate Change. Climate Change 2001: The Scientific Basis. Contribution of Working Group I to the $3^{\text {rd }}$ Assessment Report of the IPCC, eds. Cambridge University Press, Cambridge, United Kingdom and New York, NY, USA, 2001.

[18] Lashof, D.A., The use of Global Warming Potentials in the Kyoto Protocol. An Editorial Comment. Climatic Change, 44, pp. 423-425, 2000.

[19] Fuglestvedt, J.S., Berntsen, T.K., Godal, O. \& Skodvin, T., Climate implications of GWP-based reductions in greenhouse gas emissions. Geophysical Research Letters, 27(3), pp. 409-412, 2000.

[20] Archer, D., Fate of fossil fuel $\mathrm{CO}_{2}$ in geologic time. Journal of Geophysical Research, 110, pp. 1-6, 2005.

[21] Shine, K.P., Fuglestvedt, J.S., Hailemariam, K. \& Stuber, N., Alternatives to the Global Warming Potential for comparing climate impacts of emissions of greenhouse gases. Climatic Change, 68, pp. 281-302, 2005.

[22] Harvey, L.D.D., A guide to Global Warming Potential (GWPs). Energy Policy, 21, pp. 24-34, 1993.

[23] IPCC, 2006 IPCC Guidelines for National Greenhouse Gas Inventories. Prepared by the National Greenhouse Gas Inventories Programme Eggleston H.S., Buendia L., Miwa K., Ngara T. and Tanabe K., eds. IGES, Japan, 2006.

[24] DGERM, http://dgerm.attivitaproduttive.gov.it/dgerm/. 